intervals varying from two to five minutes' duration, I counted six of these discharges, and following each discharge there came a gentle tremulous movement. Immediately after the last movement, heavy rain fell, and at 1.55 there were several flashes of very vivid lightning accompanied by loud peals of thunder. The rain continued to fall during all yesterday and last night.

Although Dominica is essentially of volcanic origin, and contains at the present day three active geysers, called respectively the Souffrière, the Walton Waven, and the Boiling Lake, no unusual quantity of sulphurous or mephitic vapours have lately been noticeable in the atmosphere; in fact, only one of the phenomena usually attending earthquakes preceded the shocks I have just described, and that was violent rain. The planters' "dry season" may be said to begin in January and to end in July, and during these months, harvesting, i.e., sugar-making, goes on uninterruptedly. This year, however, there has been no "dry season," for 101"67 inches of rain have fallen on the east coast and $45^{\circ} 80$ on the west coast of this island.

I may add, in conclusion, that being unwell and unable to sleep, I was reading by lamplight when the shocks above described took place, and that I timed them carefully with a chronometer-watch by Barraud and Lund, which was on a chair near my bed. EDMUND WATT

Resident District Magistrate, Jeeward Islands

Dominica, British West Indies, August II

Is it True that no Animal can be shown to have made Use of Antecedent Experience to intentionally im. prove upon the Past?

I HAD a pair of yellow African singing finches last year. The hen laid twenty-two eggs during the year, three at each nesting. In early spring I gave her materials to build with. She selected cotton wool and fine clryish grass for her purpose. It was very cold weather when she built her first nest in a little basket which I fixed high up in her cage.

The nest was a mere film of cotton wool lined with a feru blades of grass. Of course the little creature could not sufficiently warm her eggs to hatch them, if they had proved fertile, which they did not.

At the end of fourteen days the cock, finding the eggs unhatched, set to work to bury them under cotton and grass (he being the only cock bird I lzad ever kept that built quite as well and as diligently as the hen did).

I then removed the eggs and the nest, and gave the birds fresh materials to build another nest with. They very soon accom. plished this, making the nest of the same materials, but thicker and more compact than the last.

Again three white eggs were laid in it, but the hen could not gel up the necessary degree of heat to hatch them, and at the end of fourteen days the cock set to work to build a third nest over them as before.

I again took away the nest and eggs, and I replaced the basket, this time covered externally with wadding and flannel, in hopes that thus I might help the hen to get up the proper temperature.

The little creatures immediately set to work to build again, but they this time built a much thicker and warmer and more compact nest than they had ever done before. The eggs proved fertile, and the process of incubation seemed to be successfully drawing to a close; but the patience of the cock did not suffice for the occasion. At the end of the tenth day he set to work to pull the ootton wool and grass about from the edges of the nest, and tried to bury the eggs as before, urging the hen to begin again also. This showed an unaccountable lack of instinct, not to say of reason; but surely the fact that the birds built each succeeding nest more and more thickly and warmly till incubation was possible indicates that they had made use of antecedent experience, and intentionally improved upon the past. These birds built a warm nest this spring, and succeeded in hatching a young one,

J. E. S.

\section{Deltaic Growths}

In NATURE, vol. xix. p. 506, a Rangoon correspondent states that the Gulf of Martaban has shallowed 100 feet since the surveys of Captains Ross and Crawford, made probably thirty years ago. He is mistaken as to the date of these surveys for this reason:-

In 1822 , at the outbreak of the first Burmese war, my father was appointed Flag Captain to Commodore Sir John Hayes's squadron, and he subsequently received the thanks of the Indian Government for, among other services, his surveys and explorations of the enemy's coasts and rivers. Now the soundings in the gulf would be about the first made. Hence the date would be 1822 , or fifty-seven years ago. This shows an average annual deposit of $I$ ' 8 foot, which, although very much less than what Mr. Doyle imagines, is yet almost incredible. May there not have been a gradual rising of the sea bottom to assist?

Adelaide, South Australia, July 16 FRASER S. CRAWFORD

\section{Sphinx (Deilephila) Lineata}

As this insect is "unquestionably rare in England," and not common anywhere ("D. Daucus, a native of North America, being placed for it"-according to Mr. Stephens-_ "in collec. tions "), perhaps I may be allowed to mention that a beautiful and perfect specimen of it was secured in my garden, on the $x 5^{\text {th }}$ inst., by my little son, William Cecil. He was attracted to its resting-place in a wigelia bush by the flight there of a common gamma, and to his credit, inclosed it gently in his hand without the slightest injury - a prize indeed for a collector eight years old !

A specimen was also sent my daughter some months ago, from Porto Fino on the Riviera di Levante, by Mr. Robert Macdonald, but it was unfortunately wrecked in the post.

Bregner, Bournemouth, August is HENRY CECrL

\section{The Recent Hail-storm}

I INCLOSE a tracing of a broken window-pane-one of the the numerous cases of damage caused by the hail-storm on the morning of the 3 rd inst. in this place. I almost fear the subject is one unworthy the attention of your readers, but I am curious to know what relation the space cut out may bear to the size of the hailstone causing it; and whether the clean and regular open. ing made would indicate an almost horizontal direction of the blow, as in the case of a bullet.

Observations of the extreme dimensions of the hailstones on that occasion are various among my neighbours, but one so large as $3 \frac{1}{2}$ inches seems incredible; and that one approaching such a size should strike a window at a right angle appears also im. probable.

42, Windsor Road, Ealing, August 20

\section{OITR ASTRONOMICAL COLUMN}

The Washington Catalogue.-A second edition, as it is termed, of this extensive and useful work has been published, and will be found to be an even more important aid to the practical astronomer than the former one, which appeared as an appendix to the Washington volume for 1871 , and to which reference bas been made in this column as the "Washington General Catalogue." Like the first edition, it was prepared for publication by the late Prof. Yarnall, who died suddenly after a few hours' illness on February 27, having been an astronomer at the United States Naval Observatory for twenty-six years. In a note prefixed to this second edition, Admiral Rodgers, the present superintendent of the Observatory, bandsomely acknowledges the extent and value of Prof. Yarnall's labours. A large majority of the observations upon which the catalogue is founded were made by him, as well as the computations, and the first printing of the work was executed under his immediate direction. It is stated that "the completed volume only reached him when he was already unconscious - an hour before his death. Astronomers will recognise in this volume not only a work of exceeding usefulness to them, but also a fitting memorial coming at the close of the long professional life of its author."

As was explained in the introduction to the former edition, the stars forming the catalogue consist mainly of stars used in observations with the zenith telescope, in the U.S. Army Surveys, in the lists of the Coast Survey, and many of Lacaille's stars mostly observed by Lacaille only. But there is a great addition of small stars, the 